\title{
Author Correction: Our food systems need inspiring and actionable vision
}

Roy Steiner

Correction to: Nature Food https://doi.org/10.1038/s43016-021-00246-4, published online 19 March 2021.

In the version of this World View originally published, the first sentence of the last paragraph was incorrect as: 'As we look toward the UN Food Systems Summit and plan for the actions that will follow, The Rockefeller Foundation will be sourcing and championing bold solutions for our food future from every corner of the planet.' The sentence should have read: 'As we look toward the UN Food Systems Summit and the global actions that will follow, The Rockefeller Foundation, in partnership with the UN Food Systems Summit Action Tracks, is supporting an inclusive search for bold solutions for our food future from every corner of the planet.' This has now been corrected.

Published online: 8 April 2021

https://doi.org/10.1038/s43016-021-00268-y

(c) The Author(s), under exclusive licence to Springer Nature Limited 2021 